\title{
DE LOS ORÍGENES DE UN URBANISMO PARA EL OCIO A LA INVENCIÓN DEL VERANO: APROXIMACIÓN A UN ANÁLISIS DE LOS TIEMPOS DE OCIO DURANTE EL PROCESO DE INDUSTRIALIZACIÓN EN ELCHE, 1884-1906
}

\author{
Mariano Monge Juárez \\ Universidad de Murcia \\ https://orcid.org/0000-0002-5832-1638
}

\section{RESUMEN}

El proceso de industrialización en Elche durante los años finales del siglo XIX (18841906) implica la transformación radical de las formas de vida y la aparición de la burguesía y el proletariado. Estos grupos sociales necesitan nuevos modos de ocio: el Ayuntamiento patrocina la creación de nuevos espacios urbanos de recreo, proliferan cafés, teatros.

El verano tiene un nuevo valor porque obreros y fabricantes se desplazan a las playas de Santa Pola durante el mes de agosto. Esta es la práctica que entendemos como invención del verano, una categoría sustancial de la construcción de la sociedad contemporánea.

Palabras clave: historia del ocio; verano; urbanismo; turismo.

From the origins of urbanism for leisure to the summer invention: Approach to an analysis of the leisure times during the process of industrialization in Elche, 1884-1906

\section{ABSTRACT}

The industrialization process in Elche during the final years of the 19th century (18841906) implies the radical transformation of life forms and the emergence of the bourgeoisie and the proletariat. These social groups need new leisure modes: the City Council sponsors the creation of new urban recreational spaces, coffee shops, theaters proliferate.

Fecha de recepción: 31 de octubre de 2019.

Fecha de aceptación: 30 de marzo de 2020.

Departamento de Historia Moderna, Contemporánea, de América y de los Movimientos Sociales. Universidad de Murcia. 30001 Campus de la Merced 30001 MURCIA (España).E-mail: mongejuarez@um.es 
Summer has a new value because workers and owners move to the beaches of Santa Pola during the month of August. This is the practice that we understand as the "invention of summer", a substantial category of the construction of contemporary society.

Keywords: leisure history; summer; town planning; tourism.

\section{INTRODUCCIÓN}

El presente artículo se circunscribe en la microhistoria o historia local. El objeto de estudio que se propone es el origen del ocio en el momento de la primera fase de la industrialización de Elche, una ciudad del sureste español, al sur del entonces Reino de Valencia, que cuenta con una población aproximada de unos 20.000 habitantes, entre la llegada del ferrocarril, en 1884 y la inauguración de la primera sala de cine permanente, el Teatro Kursaal, en 1906. Predominan las fuentes primarias, obtenidas todas ellas del Archivo Histórico Municipal (AHME), entre las que destacan la prensa y los Libros de Actas Municipales.

Las fuentes secundarias son escasas porque la filosofía de este trabajo no responde a la elaboración de un modelo de investigación, sino al análisis de los documentos desde un paradigma más expositivo que interpretativo. El artículo es simplemente una aproximación al tema complejo, el ocio, clave para entender la contemporaneidad y no se detiene en las relaciones del ocio, el recreo o el descanso con las reivindicaciones obreras, ya presentes en Elche desde la formación del Centro Obrero, en 1886,y la celebración del $1^{\circ}$ de Mayo, desde 1890. Este análisis etiológico sería muy necesario.

La vocación de esta pequeña investigación es presentar los resultados de modo que puedan ser útiles a otros investigadores de otros lugares, sin plantear modelos de interpretación desde el campo epistemológico.

El origen del ocio, como cara inversa del trabajo, del tiempo de ocio en calidad de derecho frente a la jornada laboral, y el concepto de placer social, es decir, momento en el que se disfruta de una actividad colectiva, constituye un elemento - categoría - fundamental de la sociedad contemporánea. En el caso de Elche, durante los años finales del siglo XIX, en pleno despegue de la industrialización, podemos observar los primeros pasos en la construcción de una cultura del ocio, en la que participan - aunque no por igualtodas las clase sociales, cultura que se traduce en nuevos espacios urbanos, nuevos formas de diversión en grupo, como el cine- y nuevas formas de ruptura con la cotidianeidad del trabajo, tal es caso de estancias en las playas cercanas. Se trata de una nueva forma de vida, vinculada en parte a una incipiente clase media, que va surgiendo en función del desarrollo de las actividades industriales y comerciales de la ciudad.

El ocio se convierte pronto en un producto más del sistema oferta/demanda, es decir, se desarrolla con intensidad toda una economía entorno a los diferentes negocios del ocio: cines, bailes, teatros, espectáculos o vacaciones son capaces de generar un nuevo sector productivo que irá incrementando su volumen según se vayan superando fases de expansión del capitalismo, desde finales del siglo XIX. Por otra parte, como consecuencia de estos cambios sociales, el ocio despertará el interés normalizador y recaudatorio de 
diferentes administraciones públicas, sobre todo, del Ayuntamiento, que obtendrá ingresos gracias al subarrendamiento del derecho de "Espectáculos públicos", que a su vez fijará tarifas en el interior de la población que gravarán las funciones líricas, bailes en general, bailes de máscaras, funciones gimnásticas y de prestidigitación, de circo, cinematógrafos, exposición de figuras de cera, o toros a muerte, entre otras. (Sig. 29-26)

Además, el carácter estacional de la incipiente industria alpargatera y textil genera espacios de tiempo no productivo, de tal modo que, aprovechando los días posteriores a las fiestas patronales, durante la segunda mitad de agosto, la población abandona la ciudad por unos días para establecerse en barracas improvisadas de madera en las playas de la vecina villa de Santa Pola. Se instituye así el proceso de invención del verano que tanta trascendencia va tener en la segunda mitad del siglo XX. Se gesta una nueva forma de organizar el ritmo de vida de obreros y fabricantes, que a su vez irá transformando la sociedad y la economía de Santa Pola.

También las citadas fiestas patronales, en honor a la Virgen de la Asunción, conocidas como la Festa, y dentro de ellas el Misteri, se transforman sustancialmente y adquieren una nueva dimensión, mucho más abierta a una interpretación menos religiosa, más lúdica y turística, capaz de despertar el interés de periodistas e intelectuales de España o el resto de Europa, como ocurra sobre todo tras la inauguración del ferrocarril. (El Vinalopó, 26 y 27) Conviene recordar que el arqueólogo francés Pierre París se encuentra en Elche, invitado por el archivero e historiador local, Pedro Ibarra, con la intención de asistir a la representación del Misteri, cuando es descubierto el busto ibérico, conocido posteriormente como la dama de Elche, en 1897.

\section{LA NUEVA CIUDAD, URBANISMO PARA EL OCIO: PLAZAS Y PASEOS}

Una de las características del nuevo concepto que domina el trazado de la ciudad contemporánea será la apertura de espacios abiertos que favorecen el paseo o la celebración de eventos, como la música y otros espectáculos, y la comunicación entre los vecinos.

La llegada del ferrocarril, y la ubicación de la estación en la zona norte de la ciudad, algo lejana del casco urbano, y sobre todo separada por un cinturón de huertos de palmeras pertenecientes a un Vínculo eclesiástico, hace que el notario José Gómez Aznar proponga la apertura de la ciudad hacia la estación mediante un gran paseo que la conecte la población con el ferrocarril. La construcción del Paseo de la Estación modificará la orientación del plano de gran parte de Elche. Si hasta 1884 el centro neurálgico había sido la Plaza Mayor, frente a la casa Consistorial, o la Calle del Salvador como espacio comercial permanente, la apertura de la ciudad hacia la estación de ferrocarril produce una reorientación urbana cuyo primer resultado es la reestructuración del Paseo de Bru, la Plaza de la Merced e incluso, la futura Glorieta del Dr. Campello, ésta última ya en los años noventa.

\subsection{El paseo de la estación}

Tres meses antes de la inauguración del ferrocarril, en febrero de 1884, José Gómez y Francisco Agulló, destacados miembros de la oligarquía política y económica de la ciudad, proponen ante la corporación municipal que se abra "una vía recta entre la población y la 
estación de ferrocarril" (LAM, 20/04/1884), es decir, un nuevo y extenso paseo abierto al recreo. No exento de intereses en la zona -Gómez es propietario de varios terrenos que saldrán beneficiados en el trazado del Paso de la Estación - reunido en su despacho con un nutrido grupo en el que encontramos a los hombres más influyentes de la ciudad, redacta un extenso documento en el que argumenta las innumerables ventajas de un espacio

“[...] tan extraordinario como pintoresco y sorprendente; allí tenemos pues la vía y la estación con todas sus dependencias, que en unos días no lejanos, por fortuna, se han de poner en explotación; pero tan cerca como está este ambicionado momento, todavía nos encontramos sin poder acercarnos a la estación a sus muelles y demás oficinas, como no sea invadiendo terrenos ajenos, puesto que aquellos edificios están enclavados en los que para el efecto fueron adquiridos por la empresa constructora... [...] esto se hace tan necesario y urgente, como que mañana mismo nos hemos de encontrar en un verdadero conflicto al hacerse imposible el transporte de las materias para la importación y exportación, como del producto de las industrias del cáñamo, elemento importante de riqueza del país, de los frutos, de dátiles, higos, granadas, y cereales de no menos importancia y sobre todo la comodidad de los viajeros". (Sig. 9-5-11)

El escrito convencerá a los representantes municipales, y sólo siete días más tarde de su lectura en el salón de plenos, se inician las obras, que primero consistirán en la tala de 98 palmeras el 27 de marzo de 1884, (Sig. 9-5-15) previa acuerdo con el administrador del citado Vínculo, al que pertenecían los terrenos.

Al margen de la estrategia caciquil, y de los intereses que podían mover a varios de los nombres que apoyaron el proyecto de Gómez Aznar, como fuera el caso del propio marqués del Bosch o José Pomares Álamo, entre otros, el proyecto del Paseo de la Estación significará que la ciudad contemporánea se acaba de poner en marcha. No obstante, las obras serán lentas debido a la falta de presupuesto, por lo que incluso se llegan a plantear hasta colectas populares, como la de 1886, (El Vinalopó, 14/04/1884) y donaciones particulares. (El Látigo, 7/11/1884) En 1888, se comienzan a plantar los olmos, así como otras plantas de jardín (LAM, 12/01/1888), aunque hasta 1891 no salen a subasta las obras (LAM, 11/04/1891). Los problemas económicos mantienen paralizado cualquier avance, hasta 1900, cuando se terminen parcialmente las obras y el paseo quede a falta de completar su iluminación. (El Pueblo de Elche, 30/09/1900) En abril de 1902, la corporación presenta por fin el proyecto definitivo que ha diseñado el arquitecto alicantino José Guardiola y queda prácticamente terminado. (LAM, 5/04/1902) En definitiva, el Paseo de la Estación se convierte en un gran espacio de recreo que transformará la ciudad y sus relaciones humanas. (Figura 1). 


\section{Figura 1 \\ PASEO DE LA ESTACIÓN HACIA 1901}

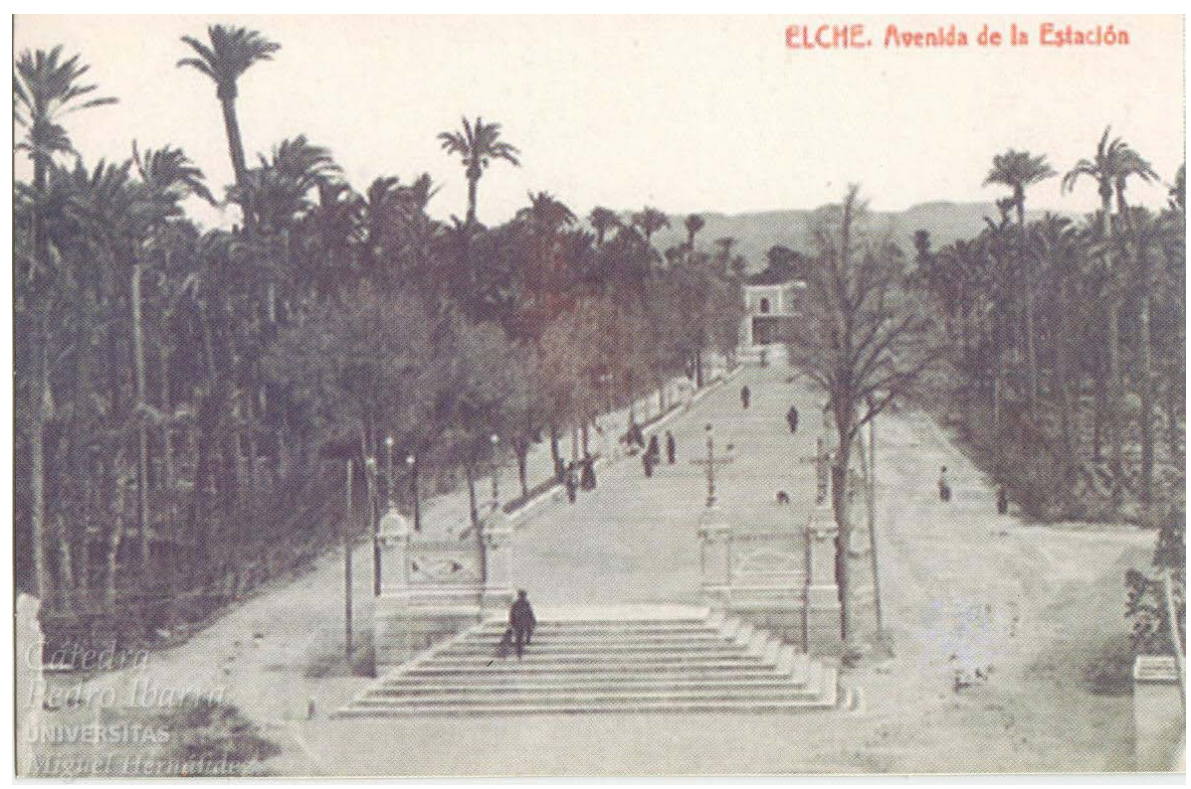

Fuente: Cátedra Pedro Ibarra, UMH.

\subsection{El paseo de Bru}

Arrastrado por la nueva orientación y reestructuración que provoca la ubicación de la estación de ferrocarril, el viejo Paseo de Bru tendrá que ser reformado a pesar de la resistencia que opongan sus vecinos. En marzo de 1885, El Bou recogerá las primeras críticas, (El Bou, 14/03/1885) críticas más intensas cuando el Ayuntamiento decida su demolición, en marzo de 1885, (El Talismán, 11/03/1885) debido a su prescindibilidad al haber construido ya el Paseo de Princesa de Asturias, y estar proyectado el de la Estación, además, el consistorio pretende conectar el citado Paseo de la Estación con la Plaza de la Merced. (Sig. 32-45) La decisión provocará muchas críticas que habrá de prolongarse durante toda la década.

Unida a la reestructuración que sufre el Paseo de Bru, en diciembre de 1887 encontramos la reforma de la Plaza de la Merced, donde es instalada una fuente ornamental que acompañará a la nueva fuente de agua potable (LAM, 6/10/1887), inaugurada con banda de música, cohetes, fuegos artificiales y volteo de campanas. (La Libertad, 18/12/1887)

\subsection{La Glorieta del Dr. Campello}

Si la estación del ferrocarril supone un nuevo polo al que se orienta la ciudad, como consecuencia de esta orientación surge la Glorieta del Dr. Campello en el solar que deja la demolición del ruinoso convento de las monjas, derribado definitivamente en 1891. La 
nueva plaza será muy importante porque constituirá un eje comercial y de comunicación que jalone la ciudad desde la plaza Mayor y la Corredora.

\section{Figura 2 \\ PLAZA DE LA GLORIETA DURANTE LA PRIMERA DÉCADA DEL SIGLO XX}

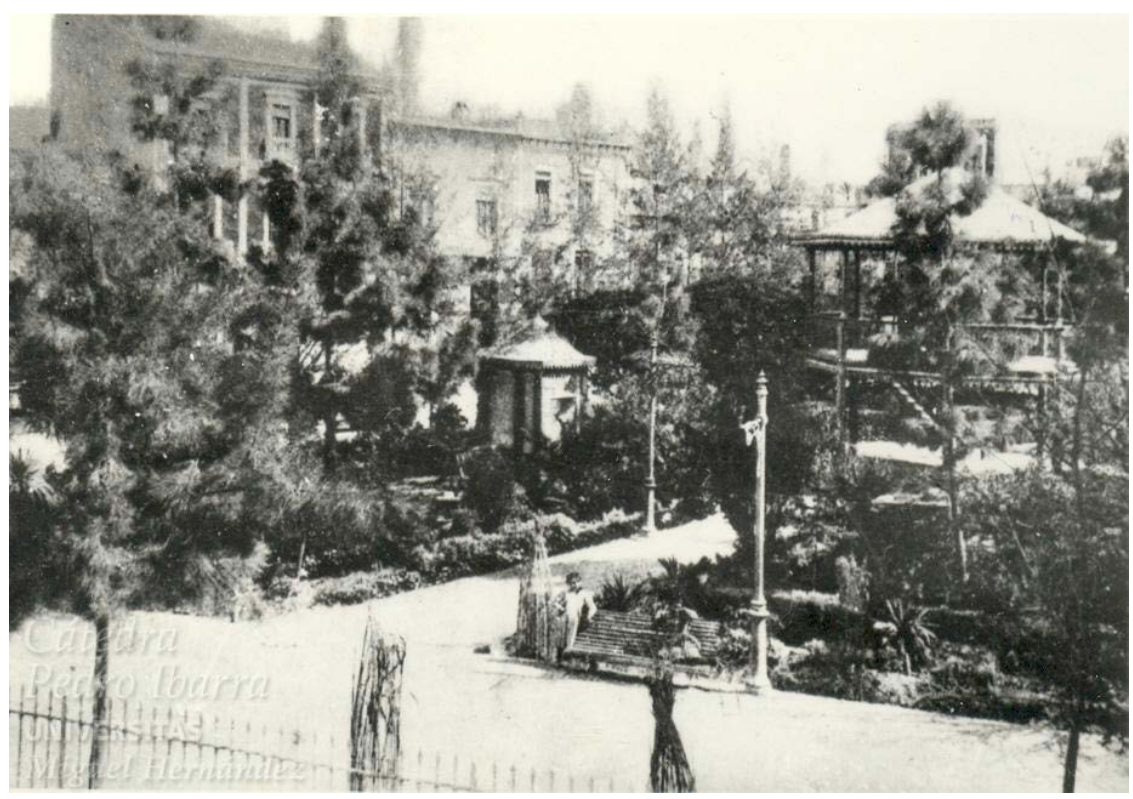

Fuente: Cátedra Pedro Ibarra, UMH.

En abril de 1885, el efecto de las lluvias torrenciales ha causado severos daños a un ya ruinoso convento que ocupa el centro de la ciudad (El Talismán, 11/03/1885), en cuyo claustro se solían celebrar espectáculos taurinos y circenses. El Alcalde y varios de sus concejales, acompañados de Manuel Campello, se presentan en el citado convento con el fin de observar los daños. (El Talismán, 16/04/1885) La corporación decidirá el derribo del edificio, que ya desde 1873 , había sido considerado un peligro para la población a causa del estado en que se encontraba. (El Pueblo, 31/05/1891) En 1891 en el nuevo solar se proyecta la construcción de una gran Glorieta pública que, por iniciativa ciudadana, dirigida por José Rodríguez, Joaquín Santo y Luis Llorente, habrá de llamarse del Dr. Campello, (Sig. 11-1-30) un conocido médico de la ciudad. No obstante, la demora de las obras permite que en dicho espacio se celebre la feria de San Andrés, (El Eco Liberal, 26/11/1891) aunque una instancia de vecinos y comerciantes solicitará del Ayuntamiento que la feria regrese a la plaza Mayor al año siguiente (Sig. 33-55). La prensa local se convertirá en uno de los sectores de la opinión pública más decididos en la defensa de la creación de la Glorieta, que asocia "con el progreso de su querida ciudad". Los principales garantes de la apertura de dicha plaza serán José Gómez Aznar y el citado Manuel Campello. (El 
Pueblo, 31/05/1891) Pero la lentitud de la burocracia y la falta de presupuesto retrasan el proyecto de una plaza que el Ayuntamiento pretende convertir en el nuevo centro neurálgico de la ciudad, como así será hasta incluso entrado ya el siglo XXI. A principios de 1896, el pleno municipal, presidido por el alcalde Jaime Brotons, encarga al ingeniero agrónomo Mariano Llofriu el diseño del nuevo espacio (LAM, 4/01/1896), que proyecta una plaza-jardín rodeada de árboles con un "parterre" (LAM, 5/04/1902) en su centro, en el que se puedan celebrar concierto de música, (LAM, 1/02/1896) y que se convierte en un gran espacio de ocio social para la ciudadanía (Figura 2).

Además de los citados, la ciudad contará con otros paseos y plazas que también serán reformados en este periodo, como el Pase de Calendura (Sig. 11-1-14) y el Paseo Chilindrón, que debido a su "deplorable estado" (LAM, 21/02/1891), y a la influencia del Paseo de la Estación, será aprobada su reforma en febrero de 1891. (El Eco Liberal, 10/05/1891)

\subsection{El planteamiento estético de la nueva ciudad}

El otro factor que hemos de unir al proceso de construcción de la ciudad contemporánea es el estético, que estará presente en muchas de las acciones del Ayuntamiento y su Comisión de Ornato. El fervor reformista y la inquietud que demuestran los ayuntamientos ilicitanos y la opinión pública con respecto a la apertura de nuevos espacios donde se desarrolle el ocio, el paseo, la música o las actividades comerciales tendrá también un objetivo estético. La ciudad aparece ante la sociedad como un sujeto de belleza.

La función estética surgirá en los años ochenta como un concepto de "revalorización de calles [y] espacios urbanos", idea derivada del progreso y la cultura de la ciudad, argumento que suele ocupar un lugar privilegiado en el discurso oficial de los políticos locales, pero también en las aportaciones de la prensa, que no sólo llamará la atención sobre las reformas municipales, sino también sobre la construcción de nuevos edificios privados, que contribuirán a embellecer la ciudad, como las casas de la nueva burguesía. Es necesario destacar en este sentido la casa de Daniel Fenoll, José Bernad, el alcalde Andrés Tarí, la fachada del casino o el hotel de José Pomares Álamo. (Sig. 2-62)

Es precisamente la cuestión estética uno de los argumentos que justificarán el proceso de normalización urbanística ya que,

“ [...] dado el grado de cultura y civilización alcanzado en esta población, cuyo rápido progreso debía armonizarse con todo lo relativo a policía y embellecimiento de la misma consideraba conducente al efecto obligar a los propietarios de fincas urbanas, al enlucido de las fachadas respectivas, siempre que necesitasen solicitar licencia del Ayuntamiento para reparar, con lo cual conseguiríamos el ejemplo de otras Ciudades alcanzado en pocos años el buen aspecto de la nuestra, proposición aprobada por una unanimidad aunque precedida de breve discusión. (El Bou, 13/06/1885)

Por otra parte, el trazado de las calles será uno de los factores que más habrá de influir la nueva estética de la ciudad, todavía en 1902, uno de los concejales propone que las calles del nuevo trazado sean rectas y que las casas "que en dicho barrio se instalen sean una mejora para el ornamento y embellecimiento de la población”. (LAM, 25/06/1891) 


\section{EL OCIO COTIDIANO}

Durante la década de los años noventa, quizá también debido a la facilidad de comunicación de la ciudad, Elche disfrutará de innumerables espectáculos, tales como la exposición de figuras de cera en la Plaza Mayor (LAM, 31/08/1902), las de la trapecista Leona Daré, (El Vinalopó, 15/04/1884) y otros también de naturaleza circense como acrobacias (El Vinalopó, 10/08/1884), prestidigitación (Los Obreros, 19/09/1886), entre las que hallamos algunas de carecer benéfico. (El Vinalopó, 8/01/1885) También hemos de citar los toros, que desde 1878, se celebran en la improvisada plaza del convento de Santa Clara hasta que se componga una plaza estable en el Cuartel Viejo. Las piñatas o bailes, ya fueran de disfraces, carnaval y de máscaras, en los distintos cafés de la ciudad como el de la estrella (El Vinalopó, 18/05/1884) o el casino, (El Vinalopó, 14/03/1886) los espectáculos pirotécnicos, de los que era principal artífice José Albarranch, (El Obrero, 14/03/1886) así como las fiestas de inauguración, de entre las que hemos de destacar la del ferrocarril, con motivo de su llegada, el 11 de mayo de 1884 (El Pueblo, 7/06/1891), la de la iluminación eléctrica o la fuente ornamental de la Plaza de la Merced, a lo que habría que añadir los primeros indicios de actividades lúdico deportivas, como la carrera de bicicletas que protagonizan en 1896, Lagier y Aznar (LAM, 25/09/1890) o la alusión a la visita que hace a la ciudad el sportman, Pedro Revenga Pascual, en 1903. (El Labrador, 7/12/1890) De la celebración de futbol no hay noticia hasta 1914, cuando se celebren partido que enfrenten a escuadras locales con otras procedentes de municipios cercanos, eventos que serán capaces de concentrar a varios miles de espectadores. (Gambín, 1998: 22)

\subsection{El ocio tradicional}

Como ya hemos dicho, las fiestas patronales, y sobre todo la Festa, experimenta un importante cambio en sus funciones, que sin dejar de ser religiosas y populares, se refuncionalizan dentro de la cultura local y se convierten en un motivo para la visita de numerosos intelectuales y turistas a la ciudad. Por otra parte, la burguesía y el pueblo reactivan fiestas tradicionales, como la costumbre de exhibir "les belles de serra" en los balcones de las casas más destacadas en la ciudad, grandes muñecas de trapo que suelen confeccionar jóvenes solteras, hecho en el que se solapa la cultura de género y de clase.

En cuento a las fiestas de la Virgen, cuya financiación correrá a cargo principalmente de los donativos de los gremios y las clases con mayor poder adquisitivo de la ciudad, desde finales de los años ochenta se cuida especialmente el cartel anunciador y el programa de fiestas, así como la ornamentación e iluminación.

\subsubsection{El teatro en la ciudad}

El teatro es la forma de ocio y creatividad más importante que vive la ciudad finisecular ilicitana. Hemos de interpretar su auge durante la década de los noventa y primeros años del siglo XX como una de las categorías que define el nuevo en la ciudad, sobre todo debido a tres causas: primera, el teatro significa un espacio concreto de ocio colectivo, que anticipa la importancia de lo audiovisual y se convierte en una fuente información y 
comunicación ideológica de gran efecto en las masas de población; segundo, en el auge del teatro ilicitano encontramos una considerable participación de la cultura popular, debido al éxito de piezas en valenciano, que acercan al gran público a las salas locales; y tercero, el teatro adquiere pronto un contenido de clase, tanto que se constituye en uno de los pilares de la cultura obrera en la ciudad.

Durante el siglo XVIII y gran parte del XIX, el teatro profano había permanecido prohibido en la ciudad debido a la gran influencia de los jesuitas (Sig. H-180-58). Pero durante la segunda mitad del siglo XIX el teatro irá surgiendo y proliferarán nuevas salas, como el Teatro de Elche, el Teatro Nuevo, el Gran Teatro o Teatro Llorente, (Sansano y Castaño, 1997) inaugurado en 1863. La proliferación de estas salas es un indicio de los cambios sociales que ya se encuentran presentes en la sociedad en la década de los años sesenta. Durante los años ochenta se producirá una nueva oleada de aparición de teatros, según Sansano y Castaño surge el Teatro Recreo - también conocido como Teatro Coliseo-, inaugurado en 1884, la pequeña sala que a partir de 1887 tendrá el Casino tras su reforma, (Sansano y Castaño, 1997: 52-53) a los que podríamos añadir la existencia a partir de 1895 del Teatro Vital Aza. De modo que durante la década de los noventa, en una ciudad de aproximadamente unos 20.000 habitantes de los cuales, algo más de la mitad son población urbana, se mantienen unas cuatro salas de teatro que ofrecen todo tipo de espectáculos, tanto tragedias como comedias o zarzuelas, género en auge en el que hay que destacar La Brusa, de Torres i Brotons y música de Rico, con un argumento especialmente crítico con el caciquismo. Además, hemos de incidir en la importancia que gana el teatro en valenciano en forma de sainete, que se introducen entre los actos de obras dramáticas, escritos por autores locales como José Pérez Sánchez, Luis G. Llorente, José Rico Gómez o Vicente Alarcón Maciá. (Sansano y Castaño, 1997: 52-53) Entre 1885 y 1900, se podría aventurar una media de unos 30 o 40 obras de teatro por temporada, de las cuales, al menos un $10 \%$ será en valenciano. Los autores de ámbito nacional más representados serán José Zorrilla, M. J. de Larra, Echegaray y E. Escalante, F. Palanca i Roca, o Alejandro Dumas. (Sansano y Castaño, 1997: 578-588)

Parece evidente que a partir de mediados de los años ochenta, las programaciones se hacen más populares, los precios son más económicos (Sig. 11-5-11) e incluso aparece una nueva modalidad de explotación de la salas, el "teatro por horas", que permite al público entrar al teatro para asistir sólo a una o dos piezas de la programación. Este auge del teatro explicará la aparición de compañías locales de actores aficionados, dirigidos por Luís G. Llorente de las Casas o su hijo, Luís G. Llorente Aguilar-Tablada, que representarán títulos locales de mayor éxito, como El tenorio de Alsabares, de Vicente Alarcón estrenada en el Teatro casino en 1891 (Alarcón Maciá, 1984), "Un dilluns a casa d'un Mestre”, de José Rico Gomis, estrenada en 1887 en el Teatro Recreo, (Sansano y Castaño, 1997: 203-254), o "Tio, jovull ser un gos”, de José Pérez Sánchez, que se representa por primera vez en el Teatro del Casino, en 1887 (Alarcón, 1984).

\subsubsection{La música}

Junto al teatro, la música es el otro espectáculo en el que los ilicitanos invertirán la mayor parte de su tiempo de ocio. De hecho, en la ciudad coincidirán varias bandas de música, que con el tiempo, irán adquiriendo valores políticos y sociales, igual que ocurra 
con los orfeones o coros, tan desarrollados durante el siglo XX. Parece ser que la primera agrupación musical de la ciudad data de 1858, aunque la documentación no es concluyente. En 1884, existe una banda de música, la dirigida por Antonio Sánchez, y tenemos noticia de otra, dirigida por el principal valedor de la música en la ciudad, Camilo Blasco, la del casino y la "Blanco y negro", ya en 1902 y que parece ser que, en 1903, funda una nueva banda como resultado de la fusión de dos más pequeñas. En 1886 se crea la "Sociedad Musical Cooperativa”, compuesta por guitarras, laúdes y bandurrias. (LAM, 31/05/1902) A finales de la década de los 90, proliferarán las asociaciones musicales como la que funda el maestro Alfredo Javaloyes, conocida en 1900 como "La escala". (Castaño, 2001: 32)

La música podrá ser interpretada bien en cualquiera de los teatros de la ciudad, sobre todo en las veladas literario-musicales que organiza el propio Ayuntamiento o el casino (El Obrero, 21/03/1886), al aire libre, en espacios creados para ello, como el citado parterre de la Glorieta del Dr. Campello o el paseo de Bru, y bajo la nueva iluminación eléctrica, que significará una nueva dimensión de la noche. En 1896 es inaugurada la Coral Orfeón Ilicitano, ya en 1900, tenemos el primer indicio de la existencia de otro Coro llamado Gayarre, (El Triángulo, 29/01/1885) y en 1903, será famoso el coro Euterpe, dirigido también por Javaloyes. (Castaño, 2001: 34)

\section{EL NUEVO OCIO: DEL CINEMATÓGRAFO A LA INVENCIÓN DEL VERANO}

Dos serán los factores que determinen la llegada a la ciudad de nuevas formas de ocio: la primera, las nuevas tecnologías, la segunda, la temporalidad del trabajo en la industria del calzado.

La electrificación de algunas calles de la ciudad y la consolidación de las "fábricas de luz" como nuevas industrias locales activas en la ciudad desde 1891 abre un nuevo panorama de ocio en la sociedad, ya que se alargan los horarios - la noche pierde su significado tradicional - y posibilita la llegada de nuevas tecnologías del ocio, como es el caso del cinematógrafo.

Por otra parte, la estacionalidad de la incipiente industria alpargatera y la cercanía de la costa explicarán la refuncionalización del verano como espacio de tiempo de ocio en el que el mar y la playa ejercen una gran atracción para la población.

En cuanto a la importancia del cine, durante nuestro periodo sólo hemos encontrado dos alusiones a la presencia de un cinematógrafo en la ciudad. En agosto de 1901, el semanario El pueblo de Elche publica una pequeña nota en la que da la noticia de un espectáculo de cinematógrafo, que se ofrece en la Glorieta (El Pueblo de Elche, 7/001/1900) y un año más tarde, en 1902, será el alcalde el que informe a la corporación del satisfactorio resultado que para Eduardo Gimeno está dando el espectáculo del cinematógrafo, instalado en un barracón de la Plaza Mayor. (Castaño, 2001:34)

Según Cámara Sempere, el primer espacio estable en el que se establezca ya un programa regular de cine llega a la ciudad en 1906, tras la construcción del Teatro Kursaal, sala promovida por una entidad de carácter obrero, La Nueva Economía Obrera. (Cámara Sempere, 2006: 197) 
Por último, nos ocupamos de la costumbre de pasar los meses de verano en Santa Pola, de la que tenemos indicio al menos desde 1884, (El pueblo de Elche, 18/08/1901) tiempo en que muchas familias se desplazan en carros o tartanas (Figura 3) a pasar un días en "barracas a la vora del mar", (LAM, 12/04/1902)y que constituye una de las formas de ocio más significativas de la sociedad ilicitana, sobre todo porque durante el siglo XX se convertirá en uno de los rasgos que definan el ciclo de trabajo/descanso en la ciudad. Describe la prensa local cómo la población se desplaza en "carros de mulas" y compone barracas hechas de maderas y otros materiales en donde las familias pasaban varios días. Hay "fiesta y jolgorio de noche y de día y los ilicitanos pasaban las mejores jornadas del año antes de hacerse al trabajo duro del cáñamo y la hilatura" (El Vinalopó, 20/08/1884) (Figura 4)

Igual que sucedía con la configuración de espacios propios de la burguesía, como la playa de la Concha en San Sebastián, la de la Malvarrosa en Valencia, así como innumerables balnearios, Santa Pola se convierte en el polo de atracción que contribuye a ese proceso de ordenación del ocio e invención del verano del que participa la burguesía ilicitana. El cambio de siglo y la continua expansión de la industrialización y el capitalismo suponen una nueva antropología de la forma de vida, del trabajo y el ocio, del tiempo y los espacios para todas las clases sociales que irán tejiendo diferentes biorritmos durante el siglo XX.

\section{Figura 3 \\ TARTANAS EN UNA DE LAS PLAYAS DE SANTA POLA DURANTE LOS PRIMEROS AÑOS DEL SIGLO XX}

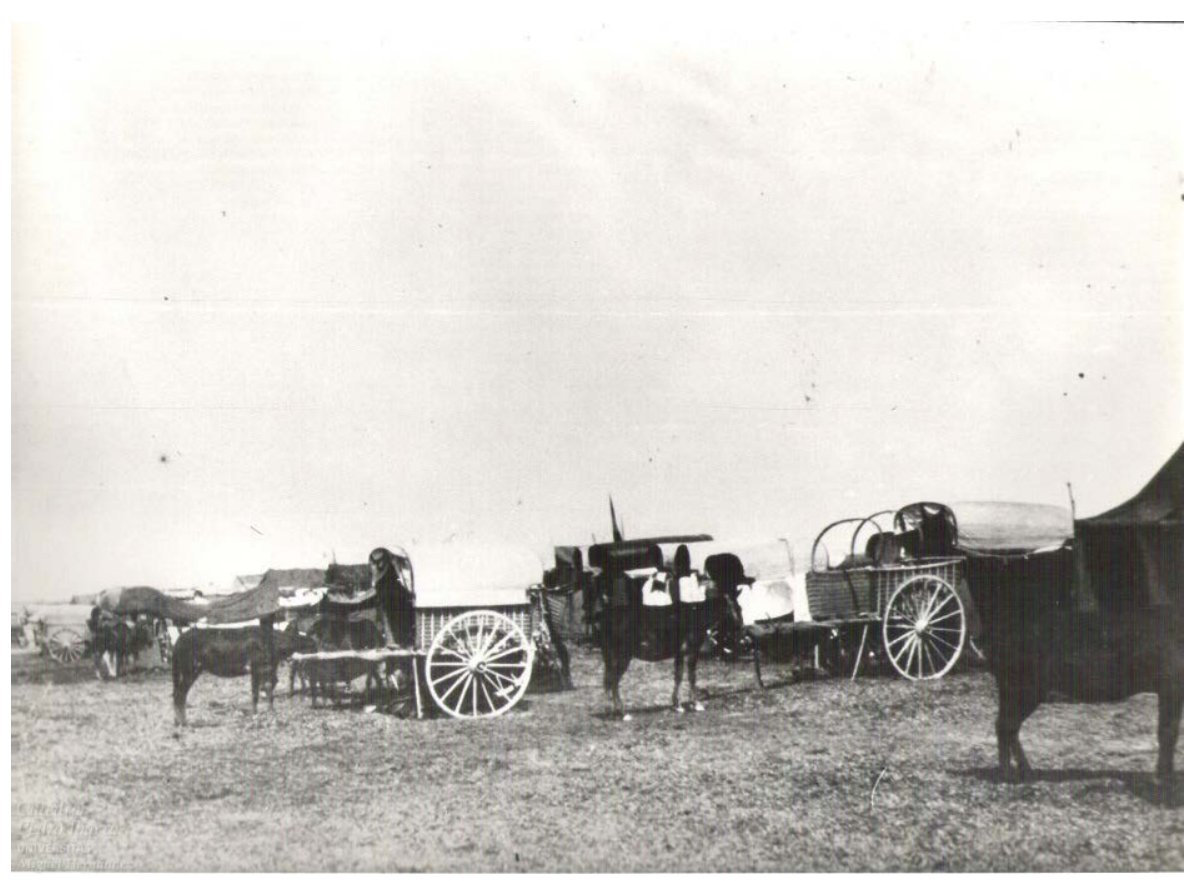

Fuente: Cátedra Pedro Ibarra, UMH. 


\section{Figura 4 \\ GRUPO DE BAÑISTAS EN UNA PLAYA DE SANTA POLA, AL FONDO LAS BARRACAS DURANTE LOS PRIMEROS AÑOS DEL SIGLO XX}

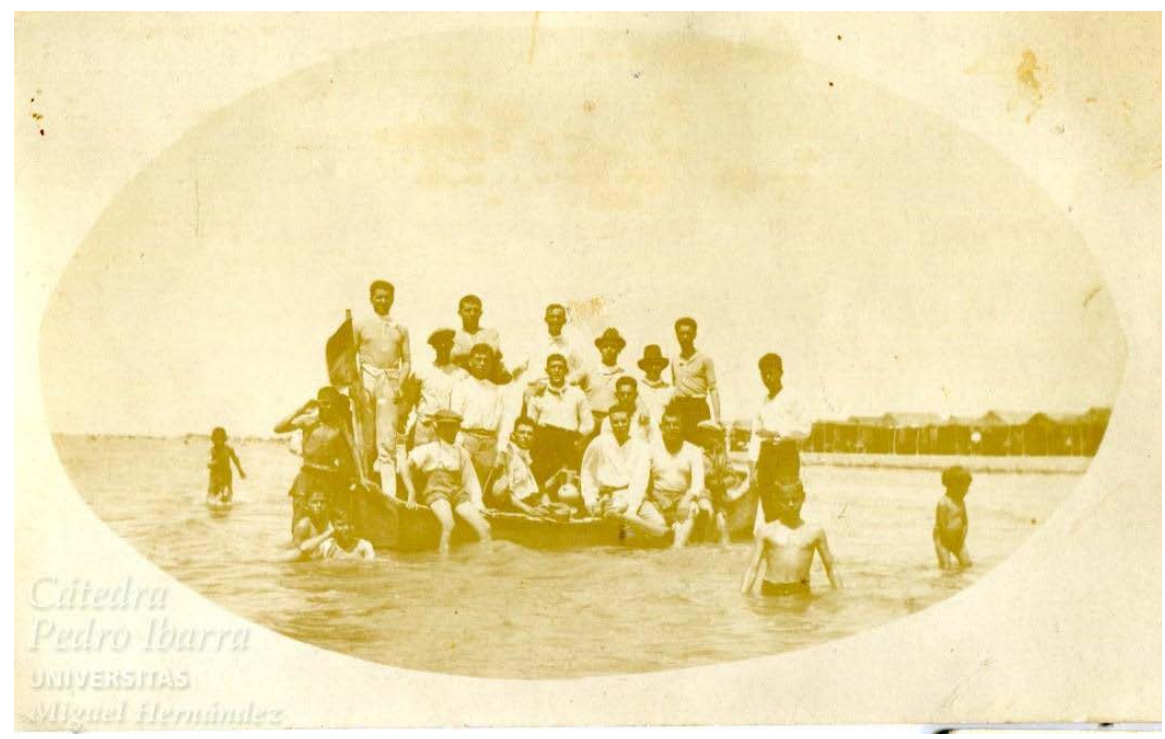

Fuente: Cátedra Pedro Ibarra, UMH.

\section{BIBLIOGRAFÍA}

ALARCÓN MACIA, V. (1984): El Tenorio de Alsabares. Comedia de costumsilisitanes. Elche, El Ramaset.

CÁMARA SEMEPERE, J.F. (2006): “El Capitolio, l'època daurada del cinema a Elx”, La Rella: anuari de L'Institut d'Estudis Comarcals del Baix Vinalopó, n 19, pp. 195-225.

CASTAÑO i GARCIA, J.. (2001): Un siglo de cultura a Elx: de l'Antic Règim a la Segona República. Elche, Instituto Municipal de Cultura del Ayuntamiento de Elche.

GAMBÍN HERNÁNDEZ, S. (1998): Setenta y cinco aniversario del Elche C.F. Elche, Ajuntament d'Elx.

SANSANO, G. y CASTAÑO, J. (1997): Sainets il-licitans de la restauración (1874-1896). (Una historia del teatre a Elx al llarg del segle XIX).Alicante, Institut de Cultura Juan Gil-Albert, Diputación Provincial.

\section{DOCUMENTACIÓN}

(LAM) Libro de Actas Municipal, sesión del 20 de marzo de 1884. (Sig. a 176. AHME) Libro de Actas Municipal, sesión del 6 de octubre de 1887. Folio 151. (Sig. a 178. AHME) Libro de Actas Municipal, sesión del 12 de enero de 1888. Folio 5. (Sig. a 179. AHME) Libro de Actas Municipal, sesión del 25 de septiembre de 1890. (Sig. a 181. AHME) 
Libro de Actas Municipal, sesión del 21 de febrero de 1891. (Sig. a 182. AHME) Libro de Actas Municipal, sesión del 11 de abril de 1891. (sig. a 182. AHME) Libro de Actas Municipal, sesión del 25 de junio de 1891. (Sig. 182. AHME) Libro de Actas Municipal, sesión del 4 de enero de 1896. (Sig. a 187. AHME) Libro de Actas Municipal, sesión del 1 de febrero de 1896. (Sig. a 187. / Sig. P-9-1.AHME)

Libro de Actas Municipal, sesión del 31 de mayo de 1902. (Sig. a 195. AHME) Libro de Actas Municipal, sesión del 5 de abril de 1902. (Sig. a 193 I. AHME) Libro de Actas Municipal, sesión del 12 de abril de 1902. (Sig. a 193 III. AHME) Libro de Actas Municipal, sesión del 31 de agosto de 1902. Folio 80. (Sig. a 195. AHME) El Eco Liberal, número 6, del 10 de mayo de 1891. (PH-9. AHME)

El Eco Liberal, número 34, del 26 de noviembre de 1891. (PH-9. AHME)

El Bou, número 2, del 14 de mars de 1885. PH-89. AHME.

El Bou, número 15, del 13 de Chuñ de 1885. (PH-89. AHME)

El Bou, número 40, del 13 de desembre de 1885. (PH-146. AHME)

El Látigo, número 2, del 7 de noviembre de 1886. PH-84. AHME)

El Obrero, número 3, del 14 de marzo de 1886. (PH-84. AHME)

El Obrero, número 4, del 21 de marzo de 1886. (PH-84. AHME)

El Pueblo, número 3, del 31 de mayo de 1891. (PH-86. AHME)

El Pueblo, número 4, del 7 de junio de 1891. (PH-86. AHME)

El Pueblo de Elche, número 46, del 7 de enero de 1900. (PH-13. AHME)

El Pueblo de Elche, número 84, del 30 de septiembre de 1900. (PH-13. AHME)

El Pueblo de Elche, número 125, del 18 de agosto de 1901. (PH-14. AHME)

El Pueblo de Elche, número 142, del 3 de noviembre de 1901. (PH-14. AHME)

El Triángulo, número 1, del 29 de enero de 1885. (PH-84. AHME)

El Talismán, número 2, del 11 de marzo de 1885. (PH-84. AHME)

El Talismán, número 7, del 16 de abril de 1885. (PH-84. AHME)

El Vinalopó, número 4, del 8 de marzo de 1884. PH-39. AHME)

El Vinalopó, número 5, del 15 de marzo de 1884. (PH-39. AHME)

El Vinalopó, número 14, del 18 de mayo de 1884. (PH-84. AHME)

El Vinalopó, número 23, del 20 de julio de 1884. (PH-39. AHME)

El Vinalopó, número 26, del 10 de agosto de 1884. (PH-39. AHME)

El Vinalopó, número 26 y 27, del 10 y el 21 de agosto de 1884. (PH-39. AHME)

El Vinalopó, número 49, del 8 de enero de 1885. (PH-84. AHME)

El Vinalopó, número 76, del 7 de marzo de 1886. (PH-84. AHME)

El Vinalopó, número 77, del 14 de marzo de 1886. (PH-84. AHME)

Gente Nueva, número 27, del 20 de diciembre de 1903. (PH-86. AHME)

La Libertad, número 1, del 13 de febrero de 1887. (PH-89. AHME)

La Libertad, número 43, del 18 de diciembre de 1887. (PH-89. AHME)

La Voz de la Verdad, número 1, del 30 de marzo de 1902. (PH-9.AHME)

Los Obreros, número 3, del 19 de septiembre de 1886. (PH-84. AHME)

Nueva gente, número 6, del 26 de julio de 1903. (PH-86. AHME)

"Correspondencia" Sig. D-94. A

"Expediente de demolición del paseo de Bru y reconstrucción del mismo". (Sig. 32-45. AHME) 
Sig. 9-5-15. AHME.

Sig. 9-5-11. AHME.

Sig. 11-1-14. AHME.

Sig. 11-1-30. AHME.

Sig. 29-26. AHME

Sig. 33-55. AHME.

Sig. H-180-58.AHME. 